\title{
Differential Staining of DNA Strand Breaks in Dying Cells by Non-radioactive in situ Nick Translation
}

\author{
Satoshi Hashimoto ${ }^{1,2}$, Takehiko KoJI ${ }^{1}$, Jianzho NIU $^{1}$, Takashi KanematsU ${ }^{2}$ and Paul K. NaKANE ${ }^{1}$ \\ Third Department of Anatomy ${ }^{1}$ and Second Department of Surgery ${ }^{2}$, Nagasaki University School of Medicine, Nagasaki, Japan
}

Received December 3, 1994

\begin{abstract}
Summary. Various lines of evidence indicate the involvement of DNA strand breaks (DSB) in the regulation of physiological states of cells, especially in cell death. Currently, cell death is divided into two categories, apoptosis and necrosis. As lysosomal integrity is maintained in apoptosis, while disrupted in necrosis, it is possible to assume that necrotic chromatin is exposed to digestion by various lysosomal enzymes. We have therefore investigated whether apoptotic DSB and necrotic DSB can be discriminated by in situ nick translation (INT) under various conditions of protease pretreatment. Used models of apoptosis and necrosis were the rat thymus with an intraperitoneal injection of hydrocortisone (10 $\mathrm{mg} / 100 \mathrm{~g}$ body weight (b.w.)) and rat liver with an intraperitoneal injection of $\mathrm{CCl}_{4}(100 \mu \mathrm{l} / 100 \mathrm{~g}$ b.w.), respectively. As results, we found that necrotic DSB was readily detected by INT without protein digestion, whereas apoptotic ones were not. These results indicate that the environment around DSB and/or the nature of DSB in apoptosis differs from that of necrosis, and that INT is a convenient molecular histochemical tool to discriminate both types of cell death in frozen sections.
\end{abstract}

Genome degradation is often the first irreversible event in a dying cell. The mode of cell death in eukaryotic cells is currently classified into two categories: apoptosis and necrosis (KERR et al., 1972). These two types of cell death differ both morphologically and biochemically (WYLLIE et al., 1980).

During apoptosis, morphologically the cytoplasm of cells condenses, while the nucleus also condenses, becomes fragmented (apoptotic bodies) without generalized lysosomal activation and is eventually phagocytosed by neighboring macrophages or parenchymal cells. It has been postulated that in apoptotic cell death, the first biochemical event is single-strand DNA breaks followed by double-strand DNA cleavage in the linker regions between nucleosomes (PEITSCH et al., 1993).

On the other hand, in necrotic cell death, morpho- logically the first noticeable cellular event is the swelling of membranous subcellular organelles, e.g. mitochondria and endoplasmic reticulum, followed by a loss of membrane integrity, cytoplasmic swelling, loss of nuclear basophilia, lysosomal rapture followed by release of hydrolases, chromatin destruction leading to karyolysis, and finally cell lysis (TRUMP and ARSTILA, 1971). As for the nuclear DNA, some (AFANAS'EV et al., 1986) have reported that the fragmentation of DNA occurs randomly at any sites along the DNA in necrotic cells.

Because of the differences in the sites of DNA cleavage, DNA isolated from the apoptotic cells will electrophorese with a ladder-like pattern, whereas that isolated from necrotic cells electrophoreses with a smear pattern (AFANAS'EV et al., 1986) or predominantly "smear" but "faint ladder" pattern (SCHUMER et al., 1992; FUKUDA et al., 1993). Another distinct difference between apoptosis and necrosis is that lysosomes remain intact in the former but lysed in the latter (KERR et al., 1972; WYLLIE et al., 1980). Thus, it may be assumed that the cells undergoing apoptosis are relatively free from proteolysis, and that DNA associated proteins, e. g. histones and acidic proteins, remain relatively intact, whereas the cells undergoing necrosis are subjected to generalized hydrolysis by the released lysosomal enzymes; the DNA associated proteins are also hydrolyzed and nuclear DNA is exposed.

We explored the possible difference between the microenvironment of nuclear DNA of apoptosis and that of necrosis to investigate whether cells undergoing apoptosis may be distinguished from those undergoing necrosis histochemically. Specifically, as models of apoptosis and necrosis, the thymus of hydrocortisone injected rat (WyLLIE, 1980; Sun et al., 1992) and livers of $\mathrm{CCl}_{4}$ injected rat (HoFFMAN et al., 1955), respectively, were used. To ensure the specificity of 
each model, we observed the morphological changes of each cell death by electron microscopy and lysosome integrity by the distribution of acid phosphatase. On frozen sections of the tissues, we performed in situ nick translation (INT) (ISEKI, 1986; DAWSON and LOUGH, 1988; KoJI et al., 1989; FEHSEL et al., 1991). INT detects nicks in DNA by adding nucleotides to $3^{\prime}$-hydroxyl ends in the presence of a template, extending the strand in the $5^{\prime}$ to $3^{\prime}$ direction. We also performed an in situ terminal deoxynucleotidyl transferase (in situ TdT) reaction (GAVRIELI et al., 1992; GoRCZYCA et al., 1993). The in situ TdT reaction is based on the repeated addition of a nucleotide at the 3 '-hydroxy ends of DNA by terminal deoxynucleotidyl transferase (TdT).

It was found that in the frozen sections, the nuclei of cells undergoing necrosis were heavily stained with INT and somewhat less with in situ TdT, whereas these of cells undergoing apoptosis were not stained with the either methods. When the frozen sections were partially digested with protease, the nuclei of cells undergoing apoptosis were then stained with INT. By comparing the INT stained sections before and after the protease treatment, one could distinguish necrotic cells from apoptotic cells.

\section{MATERIALS AND METHODS}

\section{Animals}

Wistar male 24 rats weighing $150-160 \mathrm{~g}$ were used. As a model of apoptosis, 3 rats were administered intraperitoneally with hydrocortisone $(10 \mathrm{mg} / 100 \mathrm{~g}$ b.w., 1 $\mathrm{ml} /$ head) dissolved in saline. As controls, saline alone was injected. Three hours later, the animals were sacrificed by cervical dislocation and the thymus was excised. As a model of necrosis, 9 rats were injected intraperitoneally with $\mathrm{CCl}_{4}(100 \mu \mathrm{l} / 100 \mathrm{~g}$ b.w. $)$ dissolved in olive oil. Controls were given an equivalent amount of saline with olive oil. At various timepoints $(12,18,24$ and $30 \mathrm{~h})$ after the injection, the liver was excised. Both of the tissues were quickly frozen with OCT compound (Miles Co., U.S.A.) and stored at $-80^{\circ} \mathrm{C}$ for hematoxylin and eosin staining, detection of DSB and DNA extraction.

\section{Electron microscopy}

For electron microscopy, 6 rats injected with hydrocortisone or $\mathrm{CCl}_{4}$ as described above were perfused via the aorta with physiological saline followed by $2 \%$ glutaraldehyde in $0.1 \mathrm{M}$ phosphate buffer, $\mathrm{pH}$ 7.4. The thymus or liver was dissected out into small pieces. The tissue blocks were immersed in the same fixative for an additional $48 \mathrm{~h}$ and postfixed for $1.5 \mathrm{~h}$ in $2 \% \mathrm{OsO}_{4}$ dissolved in distilled water, dehydrated through a series of graded ethanol and embedded in Epon. The ultrathin sections were stained with uranyl acetate and lead nitrate and examined under a JEOL 1210 transmission electron microscope.

\section{Staining of acid phosphatase activity}

The tissues were stained for acid phosphatase activity, according to BURNSTONE (1958) using an ACP kit (Muto chem., Japan).

\section{Procedures of INT}

Fresh frozen sections $(5 \mu \mathrm{m})$ were cut and placed onto aminopropyltriethoxysilane-coated glass slides. They were fixed in ethanol/acetic acid $(3: 1)$ at room temperature (RT) for $20 \mathrm{~min}$. After the washings with PBS, the sections were treated with or without proteinase K (PK) (Sigma Chemical Co., U.S.A.) in PBS $\left(1 \mu \mathrm{g} / \mathrm{ml}, 37^{\circ} \mathrm{C}, 15 \mathrm{~min}\right)$. After several washings with PBS, they were immersed in $50 \mathrm{mM}$ Tris $/ \mathrm{HCl}(\mathrm{pH}$ 7.5). The reaction of INT was conducted for $3 \mathrm{~h}$ at $37^{\circ} \mathrm{C}$ in a medium containing $50 \mathrm{mM}$ Tris/ $\mathrm{HCl}(\mathrm{pH} 7.5), 10$ $\mathrm{mM} \mathrm{MgCl} 2,0.1 \mathrm{mM}$ dithiothreitol, $50 \mu \mathrm{g} / \mathrm{ml} \mathrm{BSA}, 200$ $\mathrm{U} / \mathrm{ml}$ DNA polymerase I (Takara Co., Japan) and 20 $\mu \mathrm{M}$ each of dATP, dGTP, dCTP and biotin-11-dUTP (ENZO Diagnostics, Inc., U.S.A.) or TTP, as described previously (KoJI et al., 1989). After washings with $50 \mathrm{mM}$ Tris/ $\mathrm{HCl}$ buffer, the sections were incubated with $5 \%$ BSA in PBS for $1 \mathrm{~h}$ at RT. To detect the biotin incorporated into DNA, the sections were reacted with HRP labeled anti-biotin antibody (Vector Lab. Inc., U.S.A.) dissolved in 5\% BSA in PBS for $3 \mathrm{~h}$ at RT. The sites of HRP were visualized by utilizing $3,3^{\prime}$-diaminobenzidine, $\mathrm{H}_{2} \mathrm{O}_{2}, \mathrm{CoCl}_{2}$ and $\mathrm{NiSO}_{4}\left(\mathrm{NH}_{4}\right)_{2} \mathrm{SO}_{4}$ (ADAMS, 1981).

\section{Procedures of in situ $T d T$ reaction}

The sections were cut and placed as in the case of INT, and fixed in $4 \%$ paraformaldehyde in PBS at RT for 20 min. Pretreatment with PK was then done similarly to that of INT. After the preincubation with TdT buffer ( $200 \mathrm{mM}$ potassium cacodylate, 25 $\mathrm{mM}$ Tris $/ \mathrm{HCl}$ (pH 6.6), $0.25 \mathrm{mg} / \mathrm{ml} \mathrm{BSA}$ ) at RT for $30 \mathrm{~min}$, the reaction of TdT was conducted for $3 \mathrm{~h}$ at $37^{\circ} \mathrm{C}$ in a medium containing the TdT buffer, $0.1 \mathrm{mM}$ dithiothreitol, $1.5 \mathrm{mM} \mathrm{CoCl}_{2}, 0.2$ unit/ $\mu 1 \mathrm{TdT}$ (Boehringer Mannheim Biochemicals, Germany), $20 \mu \mathrm{M}$ dATP, $10 \mu \mathrm{M}$ biotin-16-dUTP (Boehringer Mannheim Biochemicals, Germany) (or TTP). Then the slides were reacted with the anti-biotin antibody and visualized, as described in the INT procedure.

In INT and in situ TdT reaction, as negative controls, some sections were incubated in the absence of the 


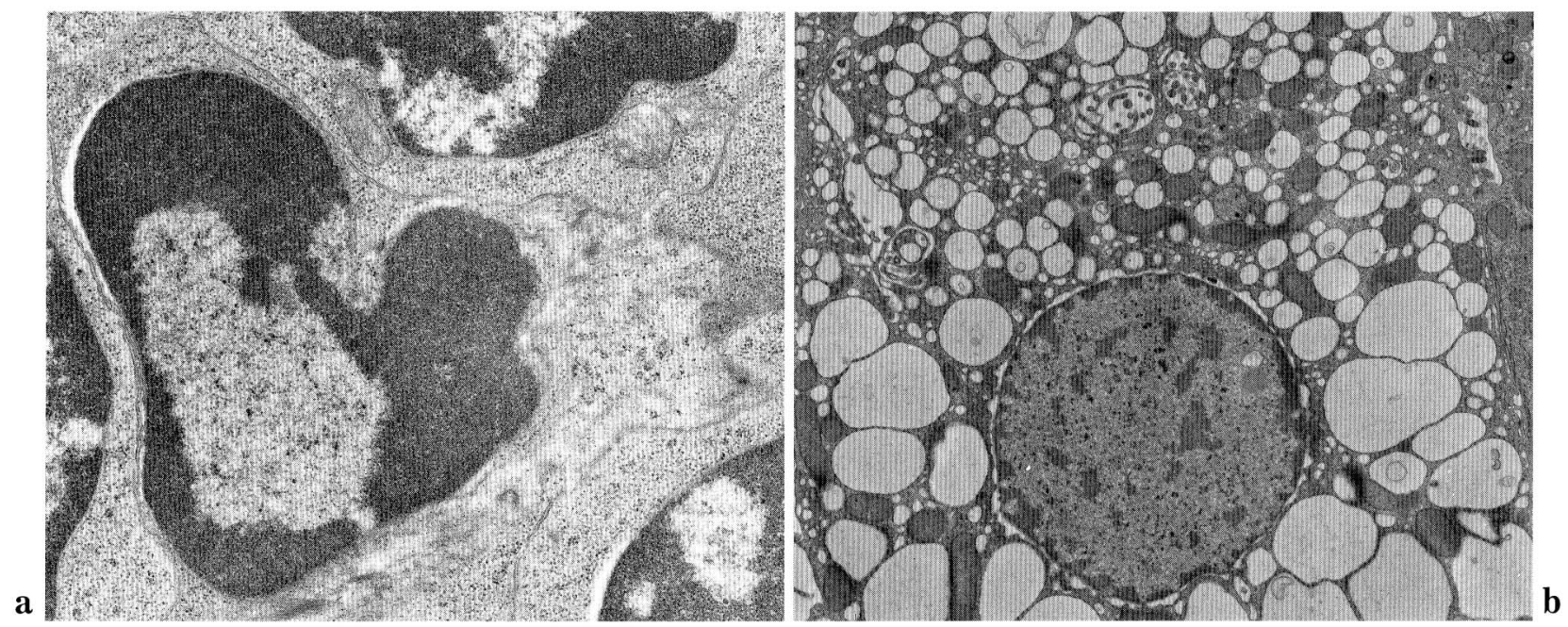

Fig. 1. Electron micrographs of hydrocortisone-treated thymocytes (a) and $\mathrm{CCl}_{4}$ treated hepatocytes (b). Note the margination of chromatin to the nuclear membrane which indicates an early stage of apoptosis (a). The necrotic hepatocyte (b) reveals swollen and disrupted cytoplasmic organelles, and an electron lucent nucleus containing scattered small coarse chromatin masses. a: $\times 12,000, \mathrm{~b}: \times 4,800$

enzyme and/or biotinylated dUTP. When biotinylated dUTP was not used, an equivalent mole of TTP was added.

\section{Electrophoresis of extracted DNA}

High molecular-weight DNA was extracted from frozen tissues as described (Kunkel et al., 1977). The concentration of DNA was measured spectrophotometrically at $260 \mathrm{~nm}$. Aliquots of the DNA samples (5 $\mu \mathrm{g} /$ lane) were separated on a $1.5 \%$ agarose gel and stained with ethidium bromide.

\section{Labeling of extracted DNA by nick translation and $T d T$ reaction}

An aliquot $(0.1 \mu \mathrm{g})$ of the extracted DNA from salinetreated thymus, glucocorticoid-treated thymus, salinetreated liver, or $\mathrm{CCl}_{4}$-treated $(18 \mathrm{~h})$ liver was labeled with biotin-11-dUTP by nick translation, or biotin-16dUTP by TdT reaction as described above. Various quantities (100 pg, $1 \mathrm{ng}, 10 \mathrm{ng}$ per spot) of the DNAs biotinylated by nick translation or tailing reaction were spotted onto nitrocellulose filters, and the biotin moieties were detected immunohistochemically by using HRP labeled anti-biotin antibody, as described above.

\section{RESULTS}

\section{Electron microscopy}

In the thymus excised $3 \mathrm{~h}$ after hydrocortisone treat- ment, many thymocytes containing a margination of chromatin (Fig. 1a) and some apoptotic bodies were recognized at the ultramicroscopic level. There were no thymocytes with ultrastructural features of necrosis.

In livers excised $18 \mathrm{~h}$ after injection, the cells located near the central vein showed features typical of hepatocytes undergoing necrosis (BASSI, 1959; TRUMP et al., 1965). In some cells, their nucleoplasms were swollen and electron lucent, with scattered small coarse chromatin masses (TRUMP et al., 1965). Some of their endoplasmic reticula were swollen or disrupted (BASsI, 1959) (Fig. 1b). No cells undergoing apoptosis were found in these livers.

\section{Acid phosphatase staining}

In the control thymus, enzyme activity was distributed in cells mainly in the medulla and corticomedullary region, and sparsely in the cortex. There was no appreciable difference in the distribution of the enzyme activity in the thymus $3 \mathrm{~h}$ after hydrocortisone treatment, when compared with that of the control (Fig. 2a, b). In the control liver section, an intense granular pattern of acid phosphatase staining was observed. In livers excised 24 or $30 \mathrm{~h}$ after $\mathrm{CCl}_{4}$ injection, routine hematoxylin/eosin staining revealed typically destroyed hepatocytes in the centrilobular area and in livers excised 18, 24, $30 \mathrm{~h}$ after injection acid phosphatase staining was decreased in the area. 


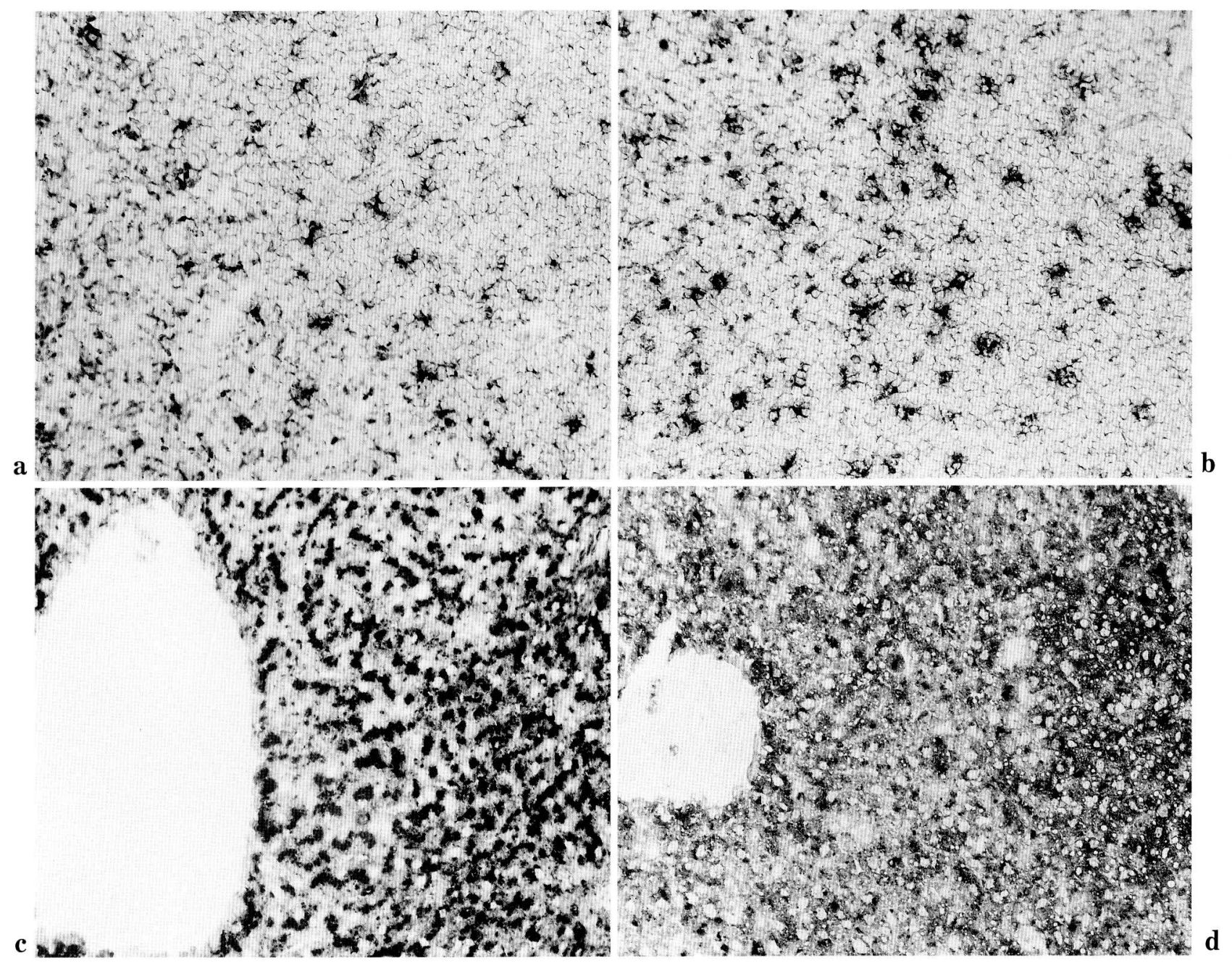

Fig. 2. Acid phosphatase staining in frozen sections of a rat thymus (a, b) and liver (c, $\mathbf{d})$. a: Saline-injected rat thymus, b: hydrocortisone-injected rat thymus, $\mathbf{c}$ : saline-injected rat liver, $\mathbf{d}$ : $\mathrm{CCl}_{4}$-injected rat liver. a-d: $\times 180$

Detection of nuclei with DSB by in situ nick translation

Ethanol: acetic acid $(3: 1)$ which was selected as an optimal fixation for INT in our laboratory was used. When sections of the thymus of saline-treated rats were subjected to INT reaction, the thymocytes were not stained, irrespective of PK digestion (Fig. 3a, b). When the frozen sections of the thymus from rats with a hydrocortisone injection were analyzed by INT, the DSB was detected in the nuclei of thymocytes, exclusively in the cortex (Fig. 3d). The intensity of nuclear staining depended upon PK digestion, and little or no staining was seen without the PK digestion (Fig. 3c).

On the other hand, heavy nuclear staining was found in the hepatocytes of central or midzonal regions of lobules $18 \mathrm{~h}$ after $\mathrm{CCl}_{4}$ injection. The staining was not affected by PK digestion (Fig. 4c, d). When the sections of saline-treated rat liver were analyzed, no signal was seen without PK digestion (Fig. 4a). However, when the sections of the control rat were treated with PK, some weak positive nuclei were found (Fig. 4b). The negative control sections for staining were essentially blank.

\section{Detection of nuclei with DSB by in situ TdT reac- tion}

As shown in Figure $5 \mathrm{a}$ and $\mathrm{b}$, TdT positive thymocytes were detected in the cortex of the thymus from hydrocortisone treated rats only when the sections were treated with PK. The number of positive nuclei detected by in situ TdT was less than that by INT. 


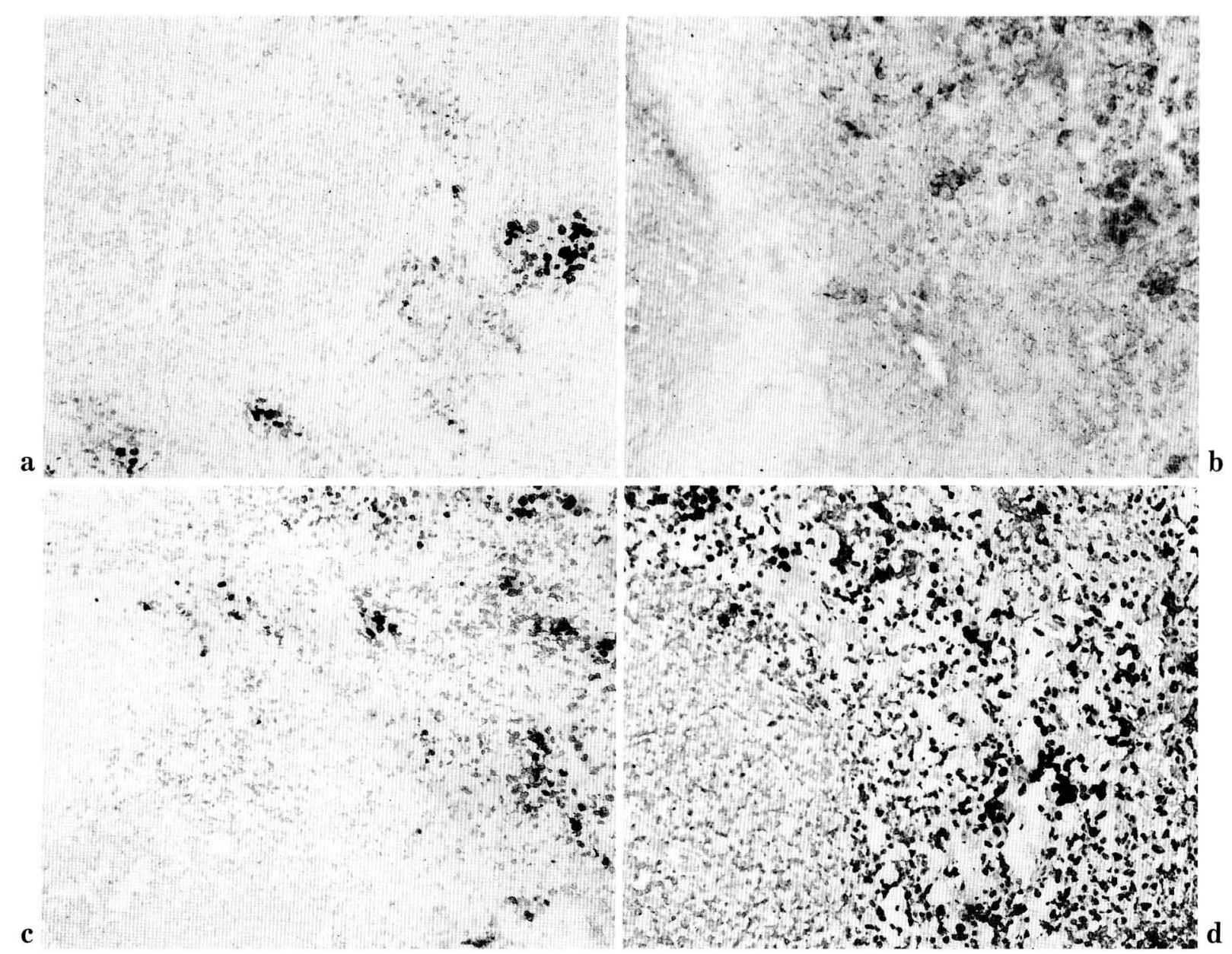

Fig. 3. Localization of DSB by INT in frozen sections of a rat thymus. Frozen sections of the thymus, from a saline-injected $(\mathbf{a}, \mathbf{b})$ or hydrocortisone-injected $(\mathbf{c}, \mathbf{d})$ rat were treated with $(\mathbf{b}, \mathbf{d})$ or without $(\mathbf{a}, \mathbf{c})$ proteinase K. a-d: $\times 180$

No staining was observed in the sections untreated with PK or in sections of the thymus of rats injected with saline. In the liver sections from $\mathrm{CCl}_{4}$ treated rats, the nuclei of hepatocytes around the central vein were stained by in situ TdT, irrespective of PK treatment (Fig. 6a, b), whereas in the liver of rats injected with saline, no positive nucleus was observed (data not shown). The negative control sections were essentially blank.

\section{Analysis of DNA strand breaks by gel electrophoresis}

The DNA extracted from the hydrocortisone-treated thymus electrophoresed in a typical ladder-like pattern. From the size marker, the ladder consisted of a series of DNA fragments in multiples of approximately 180-200 bp and a high molecular weight band. With the DNA extracted from the $\mathrm{CCl}_{4}$ treated liver,
DNA electrophoresed predominantly as a smear, while a faint, but significant, ladder pattern was also observed. DNAs extracted from thymi and livers of the saline injected control rats electrophoresed a band of high molecular weight, as shown in Figure 7.

\section{Labeling efficiency of the extracted DNAs by nick translation reaction or $\mathrm{T} d \mathrm{~T}$ reaction}

To further elucidate differences in the nature of DSB in the apoptotic cells and the necrotic cells, the extracted DNAs from the model tissues were subjected to nick translation or TdT reaction in solution, and the labeling efficiency was compared. As shown in Figure 8, by nick translation, no difference in the amount of biotin molecules incorporated was found among DNAs extracted from the normal thymus, apoptotic thymus, normal liver or necrotic liver. In 


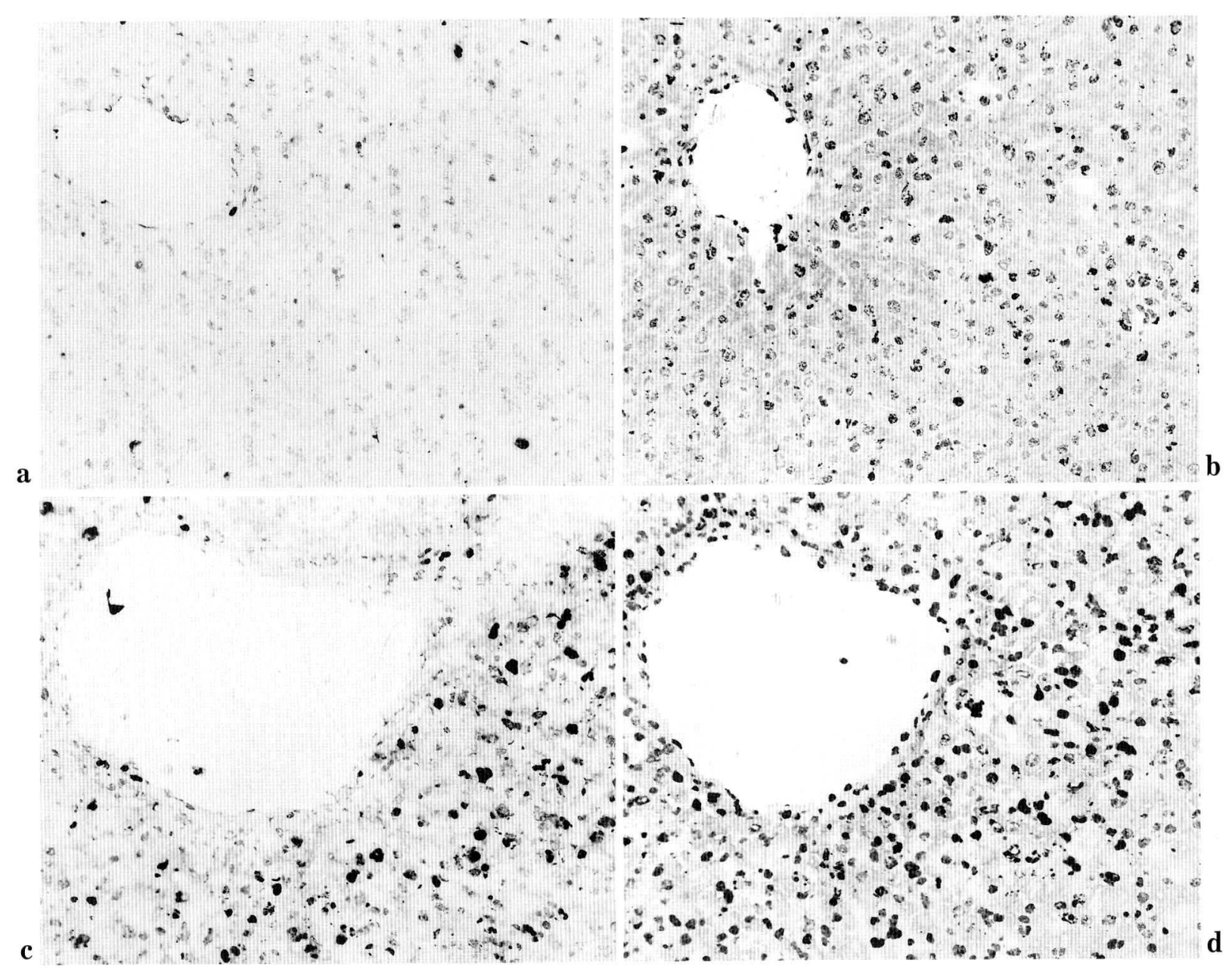

Fig. 4. Localization of DSB by INT in frozen sections of a rat liver. Frozen sections of liver from a salineinjected $(\mathbf{a}, \mathbf{b})$ or $\mathrm{CCl}_{4}$-injected $(\mathbf{c}, \mathbf{d})$ rat were treated with $(\mathbf{b}, \mathbf{d})$ or without $(\mathbf{a}, \mathbf{c})$ proteinase $\mathrm{K}$. a-d: $\times 180$

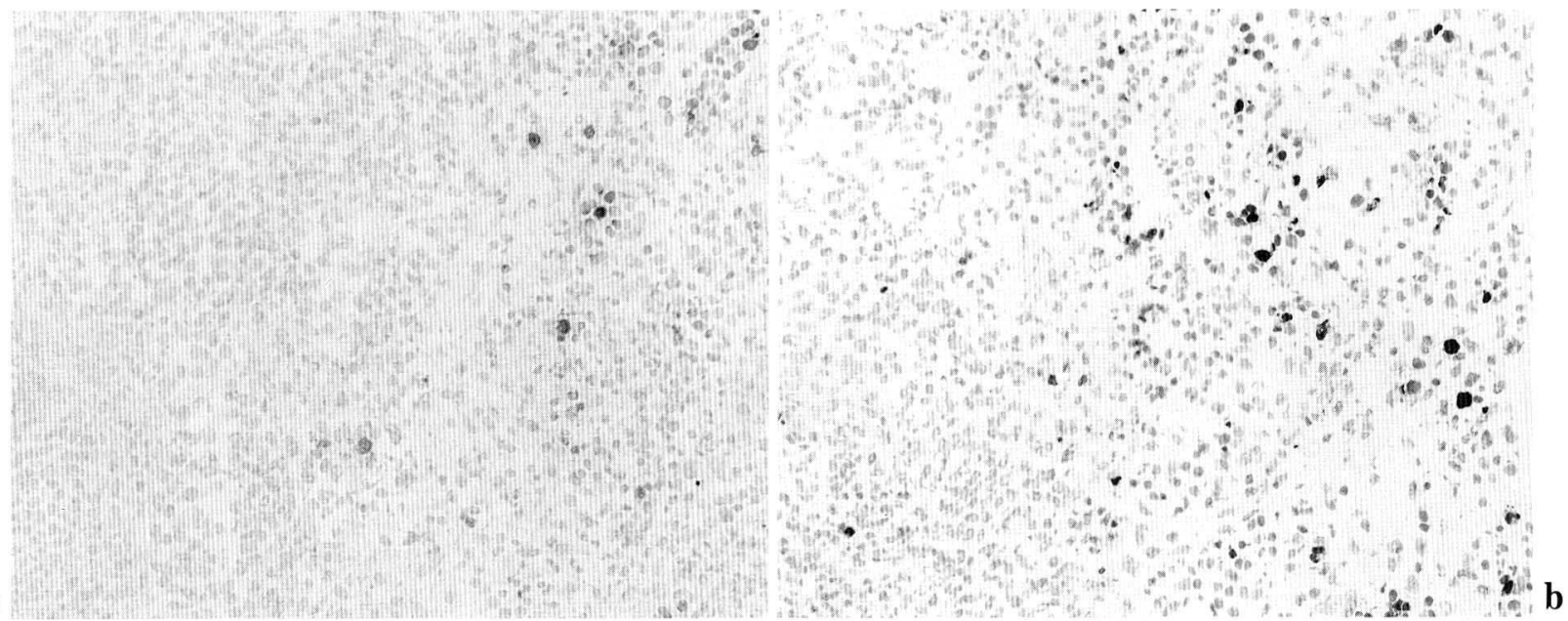

Fig. 5. Localization of DSB by in situ TdT reaction in frozen sections of a rat thymus. Frozen sections of a hydrocortisone-treated rat thymus, were treated with (b) or without (a) proteinase K. a, b $\times 180$ 


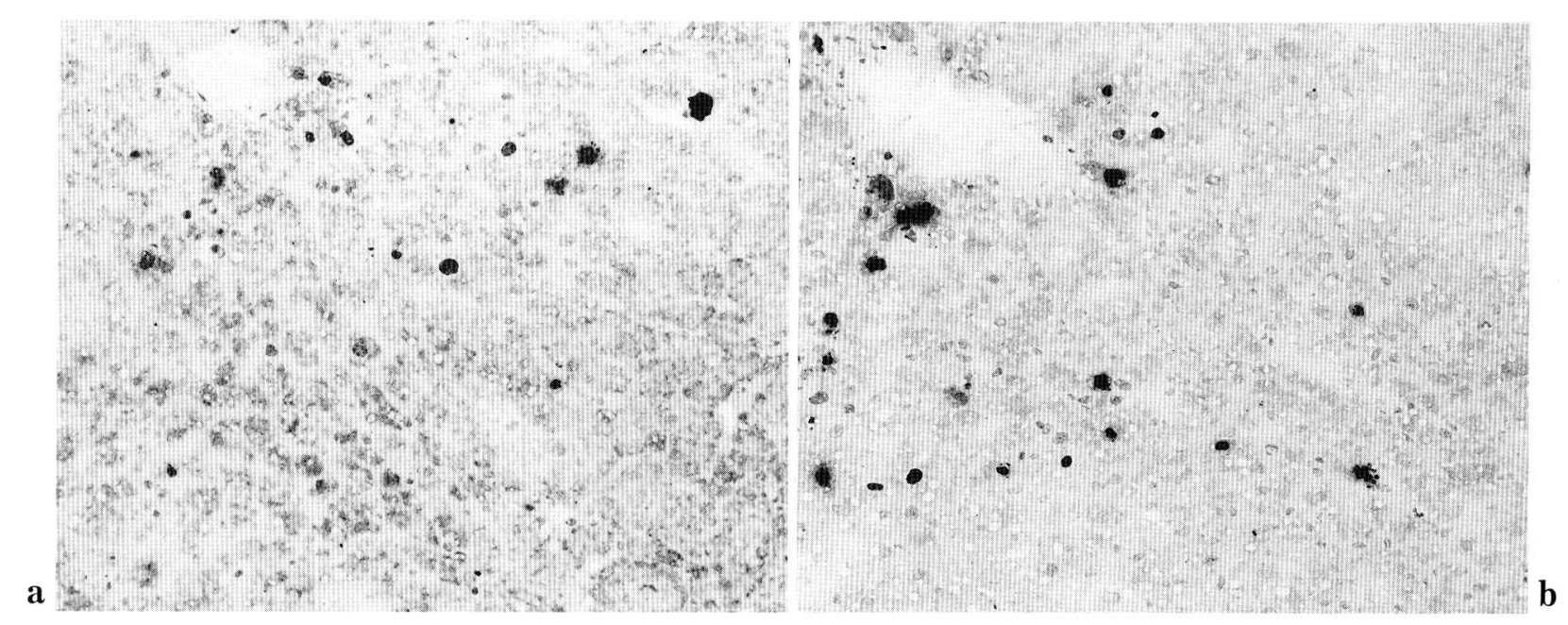

Fig. 6. Localization of DSB by in situ TdT reaction in frozen sections of a rat liver. Frozen sections of $\mathrm{CCl}_{4}$-treated rat liver were treated with $(\mathbf{b})$ or without $(\mathbf{a})$ proteinase $\mathrm{K}$. a, b: $\times 180$

all DNAs, biotin was detectable equally in less than $100 \mathrm{pg}$ of DNA. When the DNAs were reacted with TdT in the presence of biotin-16-dUTP in solution, the amount of incorporated biotin was slightly more in DNA from the thymus of a hydrocortisone-treated rat than that of a saline injected control rat, and the amount was 5-10 times more in the DNA of the $\mathrm{CCl}_{4}$ treated liver than that of the control liver.

\section{DISCUSSION}

This paper describes a method which discriminates cells undergoing apoptosis from those undergoing necrosis. The method was based upon an assumption that nuclear DNA in the apoptotic cell is mostly covered by nuclear proteins whereas that in necrotic cells is bare. The rationale of the assumption is given as follows: although lysosomes in apoptotic cells remain relatively intact (KERR et al., 1972), lysosomes in necrotic cells are disrupted (TRUMP and ARSTILA, 1971) and the released lysosomal enzymes will hydrolyze the covering nuclear proteins. It is then possible that enzymes such as DNA polymerase I and TdT will gain free access to DNA in necrotic cells and limited access to DNA in apoptotic cells. Hence, the staining intensity of nuclei by either INT or in situ TdT should be greater in necrotic cells than in apoptotic cells.

To evaluate the reliability of the proposed method, we selected the thymus of glucocorticoid injected rats as a model of apoptosis, and the liver of $\mathrm{CCl}_{4}$ injected rats as a model of necrosis. The adequacy of the thymus model was confirmed by the presence of cells

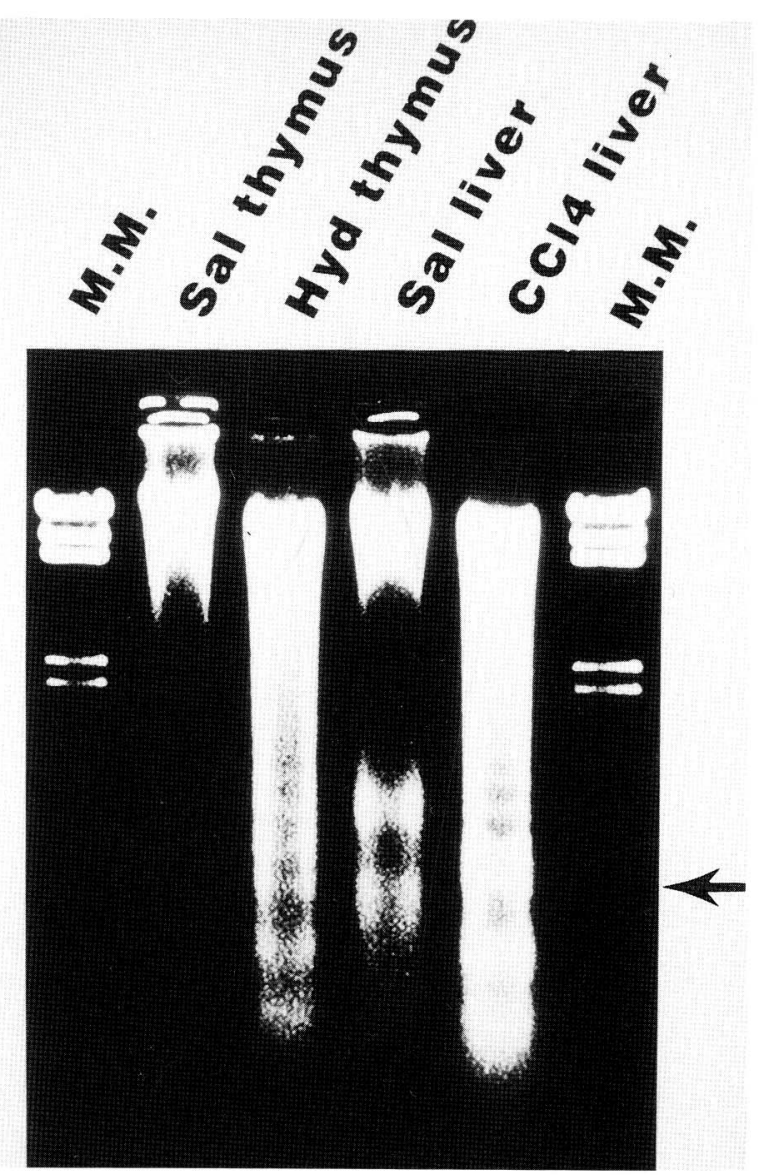

Fig. 7. Gel electrophoresis of DNA extracted from salinetreated thymus (Sal. thymus), hydrocortisone-treated thymus (Hyd. thymus), saline-treated liver (Sal liver) or $\mathrm{CCl}_{4}$-treated liver $\left(\mathrm{CCl}_{4}\right.$ liver). Lane M. M.: molecular weight marker. Arrow indicates a 564 bp DNA band. 


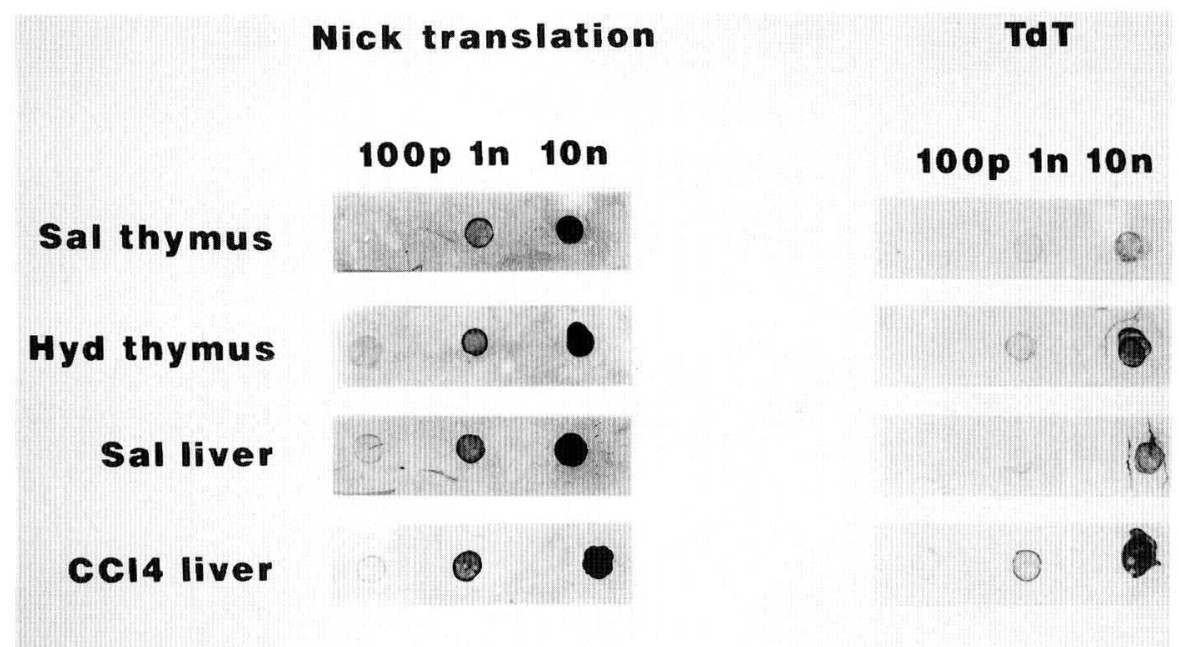

Fig. 8. Labeling efficiency of the extracted DNA by nick translation or TdT reaction. Various amounts (100 pg to $10 \mathrm{ng} / \mathrm{spot}$ ) of DNA extracted from a saline-treated thymus (Sal thymus), hydrocortisone-treated thymus (Hyd thymus), saline-treated liver (Sal liver) or $\mathrm{CCl}_{4}$-treated liver $\left(\mathrm{CCl}_{4}\right.$ liver), were reacted with DNA polymerase I or TdT, fixed onto nitrocellulose filters, and the biotin incorporated into DNA was visualized.

with ultrastructural features typical of apoptosis (KERR et al., 1972); lysosomes remained intact in the thymus, and the extracted thymic DNA electrophorese as a ladder in gel. In the liver model, suitability of the model was confirmed by the presence of cells with ultrastructural features of necrosis (WYLLIE et al., 1980) and the severe loss of lysosomal contents, and that the extracted liver DNA electrophoresed as a smear.

In those tissues where the presence of apoptotic cells or necrotic cells were confirmed, INT and in situ TdT reactions were conducted to detect DSB. In the ethanol-acetic acid fixed sections of the thymus of hydrocortisone injected rats, INT reaction stained no cells. However, after the treatment with PK, the nuclei of cells locating mainly in the cortex, where frequent apoptosis occurs, were strongly positive for DSB. On the other hand, in ethanol-acetic acid fixed sections of $\mathrm{CCl}_{4}$ injected liver, nuclei of hepatocytes located near the central veins were strongly stained after INT reaction, and the PK treatment did not enhance the staining. A similar result was obtained when the sections were fixed with paraformaldehyde and followed by TdT reaction. These observations suggest that the DSB in apoptotic cells was covered with proteins under the conditions and was inaccessible to DNA polymerase I, and only after the PK treatment did the DSB become accessible to the enzyme. However, in sections of the liver, the DSB was accessible to the enzyme prior to the PK treatment. The failure of INT reaction to stain the nuclei of apoptotic cells may be explained by that, upon fixation, proteins in the nuclear matrix agglutinate and cover the DNA including DSB and make the DSB inaccessible to reacting agents, as is observed frequently in immunohistochemistry where antigens are masked upon fixation. As in immunohistochemistry where the masked antigens are unmasked by pronase treatment (FINLEY et al., 1978), in INT or in situ TdT, when the proteins are digested partially, DSB in apoptotic cells is made accessible to the respective enzymes. As for the necrotic cells, the nuclear proteins may have been digested by leaked lysosomal enzymes prior to the fixation and no masking effect could be noticed.

By capitalizing on the differential effect of PK treatment on apoptotic cells and necrotic cells, one can discriminate apoptotic cells from necrotic cells in these tissues. Namely, after INT or in situ TdT reaction, the nuclei of apoptotic cells are negative prior to the PK treatment. In this context, it should be noted that when paraffin-embedded tissue sections were subjected to this method, no significant difference in nuclear staining of apoptotic or necrotic cells in relation to the proteinase treatment was observed (unpublished data). Therefore, unfortunately, the effectiveness of this method was limited to the frozen sections.

Both INT and in situ TdT reactions discriminate cells undergoing apoptosis and necrosis by utilizing the difference in protease response. However, the number of positive nuclei by INT was more than that by in situ TdT reaction in the thymus cortex of hydro- 
cortisone injected rats. The difference may be caused by a variety of reasons, such as differences in the reaction kinetics of DNA polymerase I and TdT, the size of the enzymes and the frequencies by which single-strand DNA breaks and double-strand DNA breaks occur in apoptosis. If the size and kinetics of the enzymes contribute to the differences, it will be extremely difficult to estimate, since the reaction rates on tissue sections are often different from those found in suspension as well experienced in the enzyme-linked immunosorbent assay (ELISA). As for the frequency, in mouse thymocytes triggered to undergo apoptosis by dexamethasone, it was reported that after electrophoresis under denaturing conditions, single-strand nicks were frequently detected in the linker regions of the chromatin DNA and even in the core particle-associated DNA, and were sensitive to the action of S1-nuclease (PEITSCH et al., 1993). Thus, it is possible that there are more single-strand breaks than double-strand breaks in apoptotic DNA, and INT identifies these single-strand breaks, whereas in situ TdT will predominantly identify the doublestrand breaks.

To estimate the degree of DSB directly, we performed labeling of isolated DNA by TdT reaction and nick translation in solution. By the TdT reaction, as expected, DNA isolated from the liver with necrosis was labeled most, followed by DNA from the thymus with apoptosis, and then DNA from the control thymus and control liver. On the other hand, there was no difference in the amounts of label incorporated into the DNAs isolated from the four tissues by nick translation. These results suggest that there are nicks which are present in living cells but are masked by proteins and are exposed when the proteins are completely digested by PK. These results also indicate that the digestion of tissue sections by PK will not expose all the nicks present in tissue sections.

The DNA extracted from the thymus of rats injected with hydrocortisone electrophoresed as a ladder, demonstrating the presence of apoptosis in the tissue. However, the DNA isolated from the necrotic liver electrophoresed with a faint, but significant ladder over smeared DNA, as was found with that of the ischemic rat liver model (FUKUDA et al., 1993). Although there is a possibility that in the necrotic models, some apoptotic hepatocytes coexisted, we found no hepatocytes with fragmented nuclei or other apoptotic appearances by electron microscopy. We speculate, therefore, that as cells undergo necrosis, some inter-nucleosomal DNA are also degraded and electrophoresed as a ladder.

This method overcomes the difficulty of distinguishing apoptotic cells by light microscopy, because the appearance of apoptotic cells presents diverse forms which are seen only a few hours before they are phagocytized. Moreover, unlike agarose gel electrophoresis, apoptotic cells are identified without losing morphological information.

\section{REFERENCES}

AdAMs, J. C.: Heavy metal intensification of DAB-based HRP reaction product. J. Histochem. Cytochem. 29: 775 (1981).

Afanas'ev, V. N., B. A. Korol', Y. A. Mantsygin, P. A. Nelipovich, V. A. Pechatnikov and S. R. Umansky: Flow cytometry and biochemical analysis of DNA degradation characteristics of two types of cell death. FEBS Lett. 194: 347-350 (1986).

BASSI, M.: Electron microscopy of rat liver after carbon tetrachloride poisoning. Exp. Cell Res. 20: 313-323 (1959).

Burnstone, M. S.: Histochemical demonstration of acid phosphatases with naphthol AS-phosphatates. J. Nat. Cancer Inst. 21: 523-539 (1958).

Dawson, B. A. and J. Lough: Immunocytochemical localization of transient DNA strand breaks in differentiating myotubes using in situ nick-translation. Devel. Biol. 127: 362-367 (1988).

Fehsel, K., V. Kolb-BaChofen and H. Kolb: Analysis of TNF $\alpha$-induced DNA strand breaks at the single cell level. Amer. J. Pathol. 139: 251-254 (1991).

Finley, L. C. W., G. H. Grossman, P. Dimeo and P. Petrusz: Somatostatin-containing neurons in the rat brain: Widespread distribution revealed by immunocytochemistry after pretreatment with pronase (1). Amer. J. Anat. 153: 483-488 (1978).

FukUda, K., M. KoJiro and J. ChIU: Demonstration of extensive chromatin cleavage in transplanted Morris hepatoma 7777 tissue: Apoptosis or necrosis? Amer. J. Pathol. 142: 935-946 (1993).

Gavrieli, Y., Y. Sherman and S. A. Ben-Sasson: Identification of programmed cell death in situ via specific labeling of nuclear DNA fragmentation. J. Cell Biol. 119: 493-501 (1992).

Gorczyca, W., J. Gong and Z. Darzynkiewicz: Detection of DNA strand breaks in individual apoptotic cells by the in situ terminal deoxynucleotidyl transferase and nick translation assays. Cancer Res. 53: 1945-1951 (1993).

Hoffman, J., M. B. Himes, S. Lapan, R. Riszki and J. Post: Response of the liver to injury. Arch. Pathol. 59: 429-438 (1955).

ISEKI, S.: DNA strand breaks in rat tissues as detected by in situ nick translation. Exp. Cell Res. 167: 311-326 (1986).

Kerr, J. F. R., A. H. Wyllie and A. R. Currie: Apoptosis: A basic biological phenomenon with wideranging implications in tissue kinetics. Brit. J. Cancer 26: 239-257 (1972).

KoJI, T., T. IshibUCHI and P. K. NAKANe: Localization of single strand breaks of DNA by in situ nick translation (INT). Cell Struct. Funct. 14: 959 (1989). 
KUNKEL, L. M., K. D. SMITH, S. H. BoYER, D. S. BoR GaONKar, S. S. W AChtel, O. J. Miller, W. R. BReG, H. W. JONES, Jr. and J. M. RARY: Analysis of human Y-chromosome-specific reiterated DNA in chromosome variants. Proc. Nat. Acad. Sci. USA 74: 1245-1249 (1977).

Peitsch, M. C., C. Muller and J. Tschopp: DNA fragmentation during apoptosis is caused by frequent single-strand cuts. Nucl. Acid Res. 21: 4206-4209 (1993).

Schumer, M., M. C. Colombel, I. S. Sawczuk, G. Gobe, J. Connor, K. M. O’Toole, C. A. Olsson, G. J. Wise and R. ButTyan: Morphologic, biochemical, and molecular evidence of apoptosis during the reperfusion phase after brief periods of renal ischemia. Amer. J. Pathol. 140: 831-838 (1992).

Sun, X., D. Dinsdale, R. T. Snowden, G. M. Cohen and D. N. Skilleter: Characterization of apoptosis in thymocytes isolated from dexamethasone-treated rats. Biochem. Pharmacol. 44: 2131-2137 (1992).

Trump, B. F., P. J. Goldblatt and R. E. Stowell: Studies of mouse liver necrosis in vitro. Lab. Invest. 14: 1969-1999 (1965).

Trump, B. F. and A. U. Arstila: Cell injury and cell death. In: M. F. LAVIA and R. B. HiLL Jr.: Principles of pathology. Oxford Univ. Press, New York, 1971 (p. 8893).
WYLLIE A. H.: Glucocorticoid-induced thymocyte apoptosis is associated with endogenous endonuclease activation. Nature 284: 555-556 (1980).

Wyllie, A. H., J. F. R. KerR and A. R. Currie: Cell death: The significance of apoptosis. Int. Rev. Cytol. 68: 251-306 (1980).
Dr. Takehiko KoJI

Third Department of Anatomy

Nagasaki University School of Medicine 1-12-4, Sakamoto, Nagasaki

852 Japan

小路 武彦

852 長崎市坂本 1-12-4

長崎大学医学部

解剖学第三講座 